\title{
Contribuições da Educação Infantil e do brincar na aquisição de linguagem por crianças surdas
}

\author{
Vanessa Regina de Oliveira Martins*, Neiva de Aquino Albres** , \\ Wilma Pastor de Andrade Sousa ** * \\ http://dx.doi.org/10.1590/0103-7307201507805
}

\section{Resumo}

O presente artigo problematiza a proposta bilíngue para crianças surdas na Educação Infantil e sua importância para o desenvolvimento linguístico do sujeito surdo. A partir da descrição de uma cena escolar em uma escola Polo bilíngue da rede municipal no interior de São Paulo, discute a aquisição de linguagem precoce e a relevância do brincar na Educação Infantil e reflete sobre a aquisição da língua de sinais nessa faixa etária, por meio da interação dialógica com o outro (surdo). Enfatiza a necessidade de políticas que estimulem a entrada da criança surda neste nível de ensino e valorizem a especificidade da surdez numa vertente bilíngue (Libras/Português) e também sugere a ampliação de escolas polos, inclusivas e bilíngues, para estudantes surdos e a adoção da língua de sinais como língua de instrução, com professores surdos e colegas surdos.

Palavras-chave: Educação Infantil, brincar, educação inclusiva bilíngue
* Universidade Federal de São Carlos -UFSCar, Centro de Educação e Ciências Humanas, Departamento de Psicologia, São Carlos, São Paulo, Brasil. vanymartins@hotmail.com

** Universidade Federal de Santa Catarina - UFSC, Centro de Comunicação e Expressão, Florianópolis, Santa Catarina, Brasil. neiva.albres@ufsc.br

*** Universidade Federal de Pernambuco - UFPE, Centro de Educação, Departamento de Psicologia e Orientação Educacionais, Recife, Pernambuco, Brasil. wilmapastor@gmail.com 


\title{
Early childhood education assistance and play in language acquisition for deaf children
}

\begin{abstract}
The article discusses the bilingual pre-kindergarten curriculum and its relevance for the linguistic development of the deaf person. Based on the description of a school scene in a public municipal school especially adapted to the needs of deaf children, the article discusses the implications, for children in this age group, of the precocious acquisition of sign language mediated by dialogical interaction with other deaf children. It advocates the need for policies that stimulate deaf children to attend this level of schooling, the bilingual approach of deaf children education, and finally the increase in the number of schools in which deaf teachers and children could meet and work together
\end{abstract}

Keywords: Pre-kindergarten stage, deafness, bilingual and inclusive education 


\section{Introdução}

O presente texto objetiva problematizar a educação infantil de crianças surdas, proposta em escolas inclusivas; com isso, apontar a baixa quantidade de alunos surdos na Educação Infantil - e, consequentemente, nos anos iniciais do Ensino Fundamental -e a necessidade de criação de políticas educacionais atrativas para a população surda, que sejam de fato bilíngues (Língua Brasileira de Sinais - Libras - e Língua Portuguesa), como aponta o Decreto 5.626/05. Neste trabalho, conceituamos educação bilíngue para surdos como aquela na qual a língua de sinais é potencializadora das relações de aprendizagens dos alunos surdos e, com isso, mobiliza mudanças curriculares significativas (Lodi \& Lacerda, 2009). Mais importante que ter a circulação da Libras na escola é, de fato, possibilitar que essa língua seja empoderada nos usos cotidianos, nas avaliações, nas salas de aulas, na relação com alunos ouvintes, tendo espaço de poder nas negociações escolares como a língua portuguesa. É ter a presença de educadores surdos que tragam para a cultura escolar aspectos culturais das pessoas surdas.

Para dar continuidade à discussão anterior, destacamos, como um dos possíveis pontos desse baixo índice de matrículas de surdos na Educação Infantil, a falta de aproximação entre educação e saúde, na consolidação de uma política pública, dentro de uma perspectiva cultural da surdez. Faz-se necessário deslocar-se da visão patológica da surdez, ainda muito enraizada na área da saúde e propiciar a questão do desenvolvimento linguístico, pela Libras, como fundamental para a criança surda, numa vertente sociocultural. Embora não aprofundemos aqui o tema da baixa quantidade de alunos surdos na Educação Infantil e nos anos iniciais, sugerimos, como uma das propostas para ampliar essa população na Educação Infantil, o investimento na disciplina de Libras na área da saúde, ainda oferecida apenas como optativa. Essa mudança de paradigma na área da saúde se faz necessária porque, sendo a língua de sinais de modalidade gestual-visual, é, portanto, a modalidade linguística mais natural para sua aquisição. Dessa forma, ao invés de investir separadamente no desenvolvimento oral de crianças surdas em espaços clínicos, o diálogo com a área da saúde facilitará o encaminhamento para a Educação Infantil com propostas bilíngues, já que essa se mostra um espaço institucional importante para o desenvolvimento linguístico do sujeito surdo. Esperamos, portanto, que nesse espaço haja uma política bilíngue que foque a aquisição de linguagem com profissionais preparados para este ofício.

Como forma de potencializar a necessidade de investimento em propostas bilíngues inclusivas para surdos, apresentaremos neste texto vivências de um projeto de 
escola Polo em um município do interior do estado de São Paulo. Isso como mote para repensar as possibilidades de promoção de espaços bilíngues para surdos em escolas inclusivas, em que se propõe uma mudança estrutural escolar. Traremos dados que mostram as polêmicas, nas redes de ensino, em torno do Decreto 5.626/05, que aponta a necessidade de escolas ou salas bilíngues, espaços de uso da língua de sinais como língua de instrução. Tal conflito ocorre porque, para alguns, como a legislação afirma que as salas devem ser de surdos e ouvintes, aquelas que se configuram, nos anos iniciais, com professores bilíngues (Libras/Português) tendo majoritariamente ou exclusivamente alunos surdos, têm sido apontadas como espaço "segregatório". Nosso foco aqui é mostrar a necessidade de salas bilíngues, com professores bilíngues em espaços nomeados de sala língua de instrução Libras na Educação Infantil e anos iniciais do Ensino Fundamental; e de professores surdos, no caso de o professor bilíngue ser ouvinte, como chave de desenvolvimento de escolas bilíngues inclusivas para surdos, além de pares surdos para a troca linguística e para a aquisição da língua de modo natural, dialógico e interativo.

Para fundamentar o artigo, apresentaremos a perspectiva bakhtiniana como balizadora dos aspectos concernentes à linguagem em uso concreto, e a relação de constituição dos sujeitos por meio de situações reais de manifestação da língua como materialização de discursos e enunciados que se processam dentro de um contexto coletivo e produtivo de saberes. Fecharemos a discussão com uma cena escolar que será aqui usada metodologicamente, por meio da análise microgenética, como narrativa de vivências que trazem o cotidiano escolar e fazem dele foco de análise, mobilizador da problematização teórica apresentada. Nesse modo de consolidar prática e teoria, os saberes que surgem do cotidiano se apresentam como dados reais que nos impulsionam ao pensar, do mesmo modo que a teoria pode oferecer instrumental para ações que melhorem a prática escolar (Góes, 2000). De modo geral, tal articulação ruma para a consolidação de políticas públicas inclusivas, de fato, na vertente educacional bilíngue para surdos. Essa é a intenção do presente trabalho.

\section{Desenvolvimento}

\subsection{Bases teóricas para pensar a linguagem e a relação com o outro na Educação Infantil}

Fundamentadas numa perspectiva dialógica da linguagem, compreendemos que estudar o humano e suas relações, mediadas pela linguagem, se configura como 
especializar-se em ciências humanas, articulando o conhecimento da sociologia, da psicologia, da linguística, entre outras ciências.

Distanciando-nos de uma perspectiva de língua como algo abstrato ou transparente e da preocupação com a forma gramatical simplesmente, apreciamos a concepção de que a língua só existe em seu efetivo uso, na interação viva entre sujeitos (Bakhtin/Voloshinov, 1999). Nesse sentido, o outro se apresenta como alteridade, ou seja, como diferença que traz consigo singularidades, aspectos culturais, modo de ser e se relacionar com o mundo e que não deve ser feito e nem efeito de um processo de homogeneização pela lógica de condicionamento do outro: eu e outro como "alter", na sua condição de ser "outro", e não de uma mesmidade subjetiva. Portanto, ambos se colocam como base de novos encontros e novos saberes. A própria diferença opera no encontro e na escuta desse outro. "Eu" e "outro", assim sendo, se complementam, se reconstroem, exatamente pela diferença e singularidade de cada um: uma interação processada na experiência do viver junto (Souza, 1994). Desse modo, a sala de aula e a interação entre professores, alunos e colegas é um espaço especial para estudar a essência da linguagem, o enunciado em ação e a construção da contrapala$v r{ }^{1}$, também nomeada como compreensão responsiva, direcionada a um outro. Nesta pesquisa, a sala de aula é apenas um dos espaços em que a construção da linguagem dialoga com os outros espaços em que os sujeitos circulam - as crianças surdas.

O enunciado humano é produto da interação entre a língua e o contexto de enunciação - contexto histórico e social. Logo, segundo Bakhtin/Voloshinov (1999), enunciação e interação são ações sinônimas. O ponto fundamental do enunciado, nessa vertente, é o dialogismo, que requer uma visão interligada dos enunciados. Cada enunciado é um diálogo com outros enunciados. As vozes se entrecruzam. Os sujeitos em interação em sala de aula estão essencialmente se constituindo do discurso do outro e assim comporão o seu próprio discurso, nada unicamente seu, mas fundamentalmente embebido do outro. E para tal ação é necessário que a interação ocorra mediada por uma língua em comum, usada por personagens envolvidos da cena enunciativa.

Apesar da função de construção de saberes e de trocas sociais de alguns espaços socioculturais como a casa/família e a escola em nossa sociedade, particularmente, para crianças surdas, diante da condição de novidade da língua de sinais por

1. Contrapalavra é a essência do processo de interação, é minha resposta como interlocutor que responde ativamente num processo de ressignificação da palavra do outro. “Compreender é opor à palavra do locutor uma contrapalavra” (Bakhtin/Volochinov, 1999, pp. 131-2). Não necessariamente a contrapalavra opera na oposição, embora a própria oposição seja significativa na produção do saber que se manifesta numa relação dialética com o outro. Ainda que seja uma complementação, as palavras do outro dirigidas a um "eu” pedem acolhimento e (re)significação. É nessa relação enunciativa que eu e outro se complementam. 
parte dos familiares, a escola torna-se o espaço principal para a aquisição de linguagem e para a interação social - quando há falantes da língua de sinais.

Bakhtin $(1999,2000)$ e o Círculo desenvolvem uma inovadora forma de compreender o complexo movimento da linguagem e da constituição do eu por meio da "poética da enunciação". Nessa perspectiva, a criança é significada e constituída pela linguagem que a cerca. E é essencialmente pelo outro interpretada.

Novamente a alteridade é um conceito que se relaciona com a possibilidade de distinção entre o eu e o outro. Ser significa ser para o outro e, por meio do outro, compreender a si mesmo. Olho-me por meio dos olhos do outro. Eu não posso fazer sem o outro, eu não posso ser eu mesmo sem o outro, devo encontrar o outro, encontrar o outro em mim (Bakhtin, 2010).

Assim os sujeitos se constituem na linguagem e por ela e constroem a linguagem e a identidade nas relações com os outros. Segundo Souza (1994), ignorar a natureza social e dialógica do enunciado é apagar a profunda ligação existente entre a linguagem e a vida. Logo, é na prática social que as escolhas linguísticas de quem produz a linguagem são reguladas pelo outro, pelo grupo social e pela situação histórica vivenciada. No caso de algumas crianças surdas, a questão da privação da linguagem por um período da vida não pode ser desconsiderada, visto que um número significativo nasce em família de pessoas ouvintes que as significam como deficientes e desconhecem a língua de sinais. A concepção da surdez e da língua de sinais de forma positiva é fundante para construir uma educação de surdos.

Em um processo de vivenciar a "poética da enunciação", na relação com os outros, a criança vai internalizando a linguagem, se apropriando do seu papel mediador, construindo conceitos e organizando seu pensamento. A criança passa da condição de ser interpretada e significada para a condição particular de construir significados sobre o mundo, sobre as coisas e as relações que vivencia:

da dependência da forma dialogal para, a partir da diferenciação dos papéis enunciativos, uma certa "autonomia discursiva"; de uma espécie de consciência dialógica para uma consciência monológica (que, no desenvolvimento linguístico-cognitivo, resultará na dialogia interna característica do discurso interior, cf. Bakhtin, 1981); da dependência do extra-textual para um progressivo apagamento da necessidade do contexto como indispensável fonte interpretativa - processos estes de objetivação da linguagem [ênfase no original] (Morato, 2000, p.160). 
Esse processo da "poética da enunciação" se configura como um processo entre o eu e o outro, ao mesmo tempo em que compreende o significado da enunciação do outro, adota uma ação em direção a ele, concorda ou discorda (no todo ou em parte).

Nessa perspectiva, concebemos a criança como um ser que significa e se constitui nas relações concretas de vida. No espaço da escola, principalmente no espaço/ atividade do brincar, as crianças se apropriam da cultura e vivenciam o simbólico, significando o mundo.

\subsection{A mediação semiótica no brincar: por uma}

\section{Educação Infantil em que se efetive o brincar pela libras}

É no espaço/atividade de brincar que a criança experiencia as formas socioculturais dos adultos, recria e assimila as normas sociais (Wajskop, 2001). Não é na mera manipulação de objetos que a criança vai descobrir a lógica dos conjuntos, das seriações e das classificações; mas é na convivência com os outros, que ela significa, por meio desses objetos, embora com outros significados, distantes do que o objeto representa. O brincar é envolvido do simbólico, da transposição do real para o imaginário.

No processo de brincar em conjunto, a enunciação proferida é incitada fora do indivíduo, influenciada pelo outro e pelas condições do meio social, uma vez que "a enunciação enquanto tal é puro produto da interação social, quer se trate de um ato de fala determinado pela situação imediata ou pelo contexto mais amplo que constitui o conjunto das condições de vida de uma determinada comunidade linguística”, considera Bakhtin/ Volochinov (1999, p. 121).

Pesquisas sobre o brincar de crianças surdas indicam que a língua de sinais é fundamental para o desenvolvimento da atividade lúdica. 0 brincar, mediado pela Libras em episódios, proporciona a possibilidade de flexibilizar a função dos objetos e a interação com outros (pares) (Silva, 2002).

Góes (2002) ressalta a necessidade de investigação do brincar em crianças surdas e aponta a dificuldade existente na interação da criança surda com os pais ouvintes em atividade lúdica no espaço domiciliar, porconta do não conhecimento dalíngua de sinais:

Julgamos que a linguagem no brincar da criança surda é um tema que tem recebido pouca atenção e que merece um esforço investigativo maior, pois envolve uma forma de atividade peculiar à infância, de grande relevância para a formação do sujeito. 0 estudo do âmbito das ações imaginativas pode somar esforços no sentido de ampliar a compreensão 
do desenvolvimento na surdez e contribuir para a discussão crítica das condições sociais oferecidas para esse desenvolvimento. (Góes, 2002, n.p.)

A autora defende ainda que a atividade lúdica é fundamental no espaço escolar, e para isso há de haver adultos sinalizadores para facilitar a aquisição de linguagem por crianças surdas. Sugere a urgência de políticas educacionais que incentivem "o brincar de crianças que se encontram em aquisição da Língua Brasileira de Sinais no contato com surdos adultos, já na etapa de Educação Infantil” (Góes, 2002, n.p.). Situação essa que beneficia sujeitos surdos, filhos de pais ouvintes. Dessa forma, "falar em mediação semiótica equivale a falar em mediação social, uma vez que tanto os meios técnicos quanto os semióticos, como a palavra², são de origem social. Isso afasta qualquer suspeita do idealismo nessa concepção" (Pino, 2001, p. 40). Assim, a organização pedagógica de uma proposta educativa bilíngue precisa levar em consideração todos esses aspectos, para conduzir a criança para seu pleno desenvolvimento, social e linguístico.

"Podemos dizer que as coisas em si não seriam totalmente conhecidas se não fossem re-conhecidas pelo pensar humano através da palavra” (Pino, 2001, p. 48). Assim, as crianças surdas, processualmente, reconhecem os sinais, os significam e ressignificam no jogo da linguagem da brincadeira (Silva, 2002).

Gestos e palavras, carregados de sentido, construídos na interlocução, na relação, no cotidiano que não é dado a priori. Gestos e palavras que são atos de enunciação, de natureza social e que não podem ser explicados a partir das condições apenas biológicas. (Bakhtin/ Volochinov, 1999, p.109)

As condições sociais de interação dialógica, bem como o modo como vivem as crianças, suas relações efetivas com a linguagem e com o outro, sejam os pais e familiares ou os outros na escola, são fundamentais para compreender sobre o processo de aquisição de linguagem. Estudar o brincar de crianças surdas em espaço de esco-

2. Palavra corresponde a signo linguístico. Dessa forma, os sinais, as expressões faciais e os movimentos do tronco compõem parte da estrutura gramatical da Libras, sendo signos fundantes para os processos comunicativos e interacionais; do mesmo modo, quando usamos o conceito de comunicação verbal, referimo-nos aos diálogos produzidos tanto nas línguas orais quanto nas línguas de sinais. la inclusiva bilíngue parece ser interessante para a análise de como elas vão significando o mundo entre surdos e ouvintes, entre língua de sinais e língua portuguesa, construindo sentido sobre o outro surdo ou ouvinte que interage com ela. 


\title{
2.3 Educação Infantil bilíngue: é possível o diálogo com as escolas inclusivas?
}

\author{
A maneira mais promissora de considerar a inclusão \\ é a que respeita e valoriza as diferenças [...]
}

(Turetta, 2006, p.7)

Balizadas pela concepção de linguagem anunciada no tópico inicial deste texto, passamos a apresentar a relação entre a educação de surdos e as escolas inclusivas com propostas bilíngues - espaço onde coletamos as análises da pesquisa, narradas aqui por meio de uma cena escolar. Dessa maneira, apontamos que adentrar na temática da Educação Infantil para crianças surdas como um processo bilíngue em escolas inclusivas é algo, primeiro, bem recente e, segundo, que desloca o próprio conceito de inclusão como relação de sujeitos diferentes convivendo em um mesmo espaço de ensino (Martins, 2008; Thoma \& Lopes, 2004, 2006; Turetta \& Góes, 2009). Isso porque, ao cogitar a possibilidade de uma escola inclusiva bilíngue, pressupomos, consequentemente, a mudança curricular para atender uma proposta visual, bem como a contratação de professores bilíngues para surdos e a promoção de salas língua de instrução Libras com a presença de surdos adultos, modelo linguístico para crianças surdas (Lodi \& Lacerda, 2009; Lodi \& Luciano, 2009; Lodi, Rosa \& Almeida, 2012; Turetta \& Góes, 2009). Mudanças que refletem concepções de ensino para surdos e que colidem com algumas propostas atuais, as quais também se articulam como promotoras de espaços inclusivos.

Assumimos, assim, a concepção à qual nos filiamos: a de surdez como resultado de uma experiência visual que promove no corpo surdo uma relação visual específica, sendo a língua de sinais constitutiva do sujeito surdo e de sua relação com a linguagem, com o mundo e com o outro (Lacerda, 2009; Lodi \& Lacerda, 2009). A Educação Infantil tem grande relevância nesse processo, como espaço de constituição de linguagem: local no qual os surdos terão a possibilidade de sua aquisição de modo mais natural, ou seja, terão a aquisição da Libras à medida que brincam, que dialogam com os colegas surdos, com os educadores bilíngues: Libras/Português, numa constituição dialógica de linguagem, conforme já descrita anteriormente (Bakhtin, 2010). Por essa razão, não vemos como funcional a atuação de intérpretes educacionais nessa faixa etária, uma vez que o aluno surdo, na maioria dos casos, não domina a língua 
de sinais, e as relações de aprendizagem por processos tradutórios ainda são muito complexas para uma criança surda que não tem no contexto familiar o uso da língua de sinais - o que ocorre na maioria dos casos.

Sobretudo, é importante destacar que a atuação do Tradutor e Intérprete de Língua de Sinais Educacional (TILSE) tem sido alvo de discussão nas políticas educacionais que tensionam a educação inclusiva de surdos. Ele tem sido convocado a atuar, inclusive, na Educação Infantil e nos anos iniciais do Ensino Fundamental - contrariando a argumentação anteriormente posta, uma vez que sua atuação se mostra meIhor nos anos finais do Ensino Fundamental e nas demais etapas de escolarização. Todavia, vale destacar que a presença do intérprete passa a ser garantida pelo Decreto 5.626/05, que regulamenta a Lei $n^{\circ} 10.436 / 02$ e o artigo 18 da Lei no10.098/2000, respondendo a questões de acessibilidade linguística amplamente discutida. Assim, vemos o fortalecimento e uma maior procura pela atuação de intérpretes de língua de sinais educacional. De algum modo, essa movimentação se reflete na regulamentação da profissão do tradutor/intérprete na Lei $n^{\circ} 12.319 / 2010$, que passa a ter um campo maior de atuação profissional.

Diante desses expostos, da necessidade de revisão do espaço escolar, da demanda de novas estratégias de acessibilidade discursiva para atender às especificidades de alunos surdos, e em razão de discussões sobre a inclusão da pessoa surda, tendo em vista a história de insucesso escolar desses alunos na escola regular, muito tem sido esperado sobre a entrada e o fazer do intérprete na instituição de ensino. Tal é a sede de respostas ao fim da "exclusão", que operam a "figura" do intérprete como aquele que, de certa forma, resolve o caos da educação de surdos, ou seja, que adentra no espaço escolar para erradicar os problemas correlatos à própria inclusão realizada, efeito de um pensamento que prevê o estar junto (a permanência de corpos em um mesmo espaço), em detrimento das mudanças estruturais e curriculares que particularizam e atendem às especificidades da surdez (Lacerda, 1998, 2006, 2009, 2010; Martins, 2008, 2013; Martins \& Souza, 2011; Thoma, 2006; Thoma \& Lopes, 2004, 2006). Destaca-se que no campo da educação "há uma visão estanque e instrumental de que a fala do professor é retida e pode ser automaticamente 'passada' ao aluno, quando houver necessidade" [ênfase no original] (Martins \& Souza, 2011, p. 76), e, dessa forma, sem mais mudanças estruturais, a inclusão se faz por meio dessa "passagem" neutra, direta e precisa de um agente que instrumentalmente se coloca, de forma clara, como objeto de transação de discursos. Poderíamos adensar a pro- 
blemática, desenvolvendo a não neutralidade e o comprometimento desse profissional, ao ser mediador de discursos. Todavia, há outra questão a destacar, não menos importante: a necessidade de revisão do espaço escolar como um todo, quando se pensa numa escola bilíngue para surdos; ou seja, o intérprete educacional é um dos protagonistas desse novo cenário. Novas mudanças curriculares se fazem urgentes para um programa bilíngue para surdos.

Da complexidade do processo inclusivo de surdos decorre que o intérprete de língua de sinais, de modo isolado, não dá conta de "resolver os problemas da inclusão", nem tem essa função (Lacerda, 2006, 2010; Martins, 2008, 2013). É um personagem que adentra no cenário escolar, mas a ele - e para o surdo, primeiramente - devem ser atreladas muitas mudanças na escola, para, assim, mobilizar modificações efetivas rumo a uma educação inclusiva de surdos.

Vale ressaltar pelo menos dois movimentos existentes atualmente, que reivindicam os discursos e os fazeres da chamada inclusão radical em prol de outras ações: A) a petição de ativistas surdos e ouvintes que defendem a manutenção de escolas de surdos bilíngues - escolas para surdos. Tal reivindicação se baseia na necessidade de professores fluentes na língua de sinais para ensinar surdos, modelos surdos na escola para aquisição de linguagem em crianças surdas, principalmente aquelas filhas de pais ouvintes, que entram na escola ainda envoltas por gestos caseiros que atendem às necessidades comunicativas primordiais da família, e as famílias acreditam que este é o melhor espaço de construção e afirmação de uma identidade cultural necessária para a construção da cidadania; B) aquele em prol de mudanças da "chamada escola inclusiva radical" para uma "inclusão bilíngue", de fato, de/para surdos, a qual prioritariamente abre espaço para mudanças, para diferenças surdas e para a entrada da experiência radical da surdez no espaço escolar - o que prevê estudos, pesquisas, orientações e ajustes no interior das práticas educativas. Não na contramão das concepções apresentadas para a manutenção das escolas de surdos, mas numa posição de enfrentamento da realidade inclusiva que impera atualmente, na tentativa de negociar, de minar por dentro e perverter o existente. Sobre esse momento de luta e conflito ideológico e político para uma posição mais ética no fazer inclusivo para surdos, Thoma (2006, p. 23) aponta que, "entretanto, as mudanças legais e os subsequentes investimentos e ações que buscam promover as mudanças de códigos e símbolos escolares (currículo, didática, metodologia e avaliação) não têm sido suficientes". Com isso, convocam-se novas ações práticas e reflexões para 
pensar e produzir uma inclusão, que seja às avessas, tendo como premissa o surdo e sua singular aprendizagem pela língua de sinais.

Nesse emaranhado de ideias e com a legislação apresentada anteriormente, que visa garantir uma educação bilíngue, germinam alguns projetos de escolas inclusivas bilíngues para surdos. Aqui cabe apresentar e marcar os projetos de escolas Polo de surdos (escolas inclusivas bilíngues) em municípios distintos no interior do estado de São Paulo (Piracicaba, Campinas, São Paulo, São Carlos), nos quais algumas de nós tivemos vivências como pesquisadoras, formadoras e educadoras. Alguns desses municípios serão aqui rememorados em trechos de vivência - nas coletas de dados que fizemos. Destacamos que a maior parte desses projetos foi assessorada e implementada pela professora Cristina B. F. de Lacerda, numa parceria entre a Universidade Federal de São Carlos - UFSCar - e as prefeituras citadas.

Alguns questionamentos surgiram deste fazer, advindos da Secretaria de Educação - mais especificamente, da Secretaria de Educação Especial -, particularmente de um dos municípios citados anteriormente, colidindo com concepções fundantes do projeto, tais como: se há necessidade de salas bilíngues de surdos nos anos iniciais do Ensino Fundamental e na Educação Infantil ou se é possível fazer tal ação a partir da presença de intérpretes educacionais, nomeados por professores bilíngues atuantes em codocência, por alegar que inclusão ideal se faz com pares surdos e ouvintes no mesmo espaço. As salas bilíngues, espaços onde a língua de instrução é a Libras, têm, por conta disso, exclusivamente surdos matriculados, embora não houvesse nenhum impedimento de entrada de estudantes ouvintes. Os questionamentos ainda consideravam se há necessidade de um grupo de estudantes surdos numa mesma sala, ou se o melhor seria cada surdo estudando em uma escola mais próxima de sua casa, já que, na reivindicação da secretaria sobre o projeto, não seria "bem vista" a aglomeração de surdos em um mesmo espaço, ou numa mesma escola, justificando-se pela vertente de que a pulverização em muitas escolas oportuniza, para mais pessoas ouvintes, a experiência de convívio com surdos.

Contrariando a argumentação anterior e para fundamentar a possibilidade de sucesso na Educação Infantil inclusiva bilíngue, a partir da perspectiva dialógica e da construção do “EU” (surdo) por meio da relação com o outro (surdo), traremos algumas reflexões a partir de uma cena escolar narrada detalhadamente. Na descrição, é significativa a mudança da aluna surda do contexto escolar da sala língua de 
instrução Libras (a qual valorizamos com espaço ideal) para a proposta de atividade em codocência: professor regente e professor bilíngue com alunos ouvintes. A partir desses dados, refletiremos sobre algumas das dificuldades apresentadas nesse novo espaço, em comparação ao sucesso que vínhamos galgando no modelo anterior. Isso para defender a eficiência das salas língua de instrução Libras como espaço possível de criação de uma escola bilíngue inclusiva. Sintetizando, tivemos exemplos de alunos surdos que, após passarem alguns anos na Educação Infantil, com contato com surdos adultos e crianças surdas, em salas bilíngues ${ }^{3}$, tiveram uma aquisição mais natural da língua de sinais e, com isso, mostraram melhores desempenhos na aprendizagem da língua portuguesa, por exemplo, no Ensino Fundamental I - dados que não aprofundaremos aqui. Notamos que, por a língua não ser mais empecilho de aprendizagem de conteúdo, nem de comunicação, a consolidação de conhecimentos fluía mais facilmente (Martins \& Lacerda, 2014) ${ }^{4}$.

Portanto, é possível pensar outra escola inclusiva para surdos? Isso só se faz, em efeito, se houver abertura para diálogos e mudanças de olhar para o espaço inclusivo e seu fazer: pensar a inclusão para além de compartilhamento de espaço de aprendizagem. Se a Libras tiver espaço dentro do currículo e se, por ela, houver mudanças significativas no cotidiano escolar. E ainda, se tivermos, nos anos iniciais, salas língua de instrução Libras, com surdos adultos como modelo linguístico. A escola, assim, se faz como espaço no qual a presença de surdos, mais que simples corpo físico, perverte o fazer. Isso só ocorre quando, de fato, "escutamos" com nossos olhos aquilo que os surdos nos "sinalizam" sobre sua educação, e o modo como aprender se torna mais real e significativo.

\section{Análise de dados}

Traremos nesta parte do texto uma cena escolar como base de diálogo da teoria anunciada. A partir da contribuição dos estudos de Góes (2000), apoiada pelas teorias de Vygotsky e Bakhtin, esta pesquisa se aplica na proposta microgenética, que tem como pressuposto analisar as interações sociais com o exame do funcionamento dialógico-discursivo (Góes, 2000). Tal proposta possibilita adentrar nas microrrelações cotidianas, trazendo
3. Sala bilíngue ou sala língua de instrução Libras é o nome dado para as salas multisseriadas em escolas inclusivas (Polo de surdos) que tinham como requisito a atuação de professores bilíngues, Libras/Português, e professores surdos. Em todo o texto, faremos uso das duas nomenclaturas para a mesma finalidade. A língua de instrução dessas salas é a Libras. Portanto, não define ser uma sala de surdos ou ouvintes, mas as aulas serão dadas em língua de sinais, do que deriva a matrícula de alunos surdos.

4. As autoras (Martins \& Lacerda) apresentam, neste artigo referido de 2014, aspectos positivos da escolarização de alunos surdos em propostas de escolas inclusivas bilíngues. Destacam como a sala multisseriada, língua de instrução Libras, tem sido promissora de práticas de letramento, numa perspectiva de ensino da língua portuguesa como segunda língua. 
uma cena como alegoria para refletir o funcionamento das práticas institucionais e dos discursos enunciados pelos sujeitos: produtores de história e de cultura. A pesquisa se realizou em uma sala inclusiva bilíngue - na qual a língua de instrução não era a Libras, contendo crianças surdas e ouvintes - da Educação Infantil (agrupamento III), em uma escola Polo, municipal, no interior de São Paulo. Foram filmados vários momentos das atividades escolares. As aulas eram ministradas em língua portuguesa, pela professora regente, e "interpretada" pela professora bilíngue para uma aluna surda. A cena, de modo geral, reflete uma forma de apontar o cotidiano como espaço de construção de saber, no qual circulam conhecimentos que devem ser motivos de adensamento reflexivo.

Portanto, aqui delineamos a metodologia usada, a de análise do cotidiano como espaço de criação, de diálogo, no qual as múltiplas vozes que o compõem imperam e conferem modos de verdade e construções de subjetividades. Portanto, apoiadas na teoria enunciativo-discursiva de Bakhtin $(1999,2010)$ e do Círculo, delineada no início deste texto, destacamos que toda análise é realizada dentro de uma historicidade, com personagens que configuram uma realidade e um sentido para o evento trazido em destaque. Somente quando participamos responsivamente do evento compreendemos as bases de sua emergência. É nesse movimento de estar no cotidiano e de deslocar-nos dele para a análise que traremos as cenas escolares como tópico e convite para teorizarmos um pouco mais.

\section{1 Narrativa sobre o cotidiano escolar de surdos na Educação Infantil}

- Cena escolar: a língua de sinais e o brincar na Educação Infantil

Descrever esta cena escolar se torna significativo, quando afirmamos a importância da aquisição da língua de sinais em tenra idade e a necessidade de pares surdos para a troca lúdica e relação simbólica imaginária. Segue a cena:

Talita ${ }^{5}$, uma aluna de 5 anos da Educação Infantil, é filha de surdos e conhece bem a língua de sinais. Está há dois anos no projeto de educação bilíngue inclusiva em uma escola da rede municipal de Campinas e vivenciou mudanças estruturais e de concepção do modelo de atendimento na Educação Infantil para surdos. Em seu primeiro ano de escola Polo, estudava em uma sala de Educação Infantil com alunos surdos, sala língua de instrução

5. Para guardar sigilo da identidade da aluna, usamos um nome fictício.
Libras, com professora bilíngue e instrutora surda. No ano de 2014, com algumas mudanças, a sala língua de 
instrução Libras, no modelo apresentado, foi encerrada, e a aluna passou a estudar em uma sala regular com colegas ouvintes. Num primeiro momento, ela estava sem a professora bilíngue e sem a instrutora surda, o que fez com que não quisesse mais ir à escola. 0s pais surdos questionaram a estrutura anterior e o oferecimento de uma sala com professor bilíngue, colegas surdos e ... um mês depois foi designada uma professora bilíngue ouvinte, fluente em Libras, para atuar em parceria na sala de ouvinte, num modelo que tem sido nomeado de "sala bilíngue em codocência": diferente da proposta anterior, sala língua de instrução Libras prioritária para alunos surdos. Como, por uma questão política da rede, que deixou de encaminhar alunos para as "escolas Polo", a aluna não tinha outros colegas surdos nessa nova sala, ela se recusava a brincar com os colegas ouvintes e se isolava com a professora bilíngue, que, na medida do possível, tentava verter a aula que era pensada para ouvintes, em um modo mais agradável e visual. Um dia, no momento do Ateliê de brincadeiras, a aluna Talita pegou peças de lego e começou a montar um cenário. Sentada com mais quatro coleguinhas ouvintes, a aluna surda tentou esboçar um sinal em Libras para uma das colegas ouvintes e, sem respostas, iniciou uma brincadeira sozinha: encenava com seus dedos pessoas caminhando pelo cenário escolar que ela criou com o lego. A professora bilíngue, observando a cena, tentou aproximar Talita dos colegas ouvintes, traduzindo a brincadeira. Então Talita sinalizou, dizendo: “brinca você comigo, eles não brincam direito esse tipo de brincadeira, só no parque". A professora passou a brincar com a aluna e então ela personificou a professora com seus dedos, a multidão entrando no espaço por ela construído, a mãe que se atrasou ao buscar a criança... Depois de um tempo de brincadeira, olhou para a professora bilíngue e fez o sinal da colega ouvinte - que tem aqui a configuração em L (LAURA) - sentada próxima a elas e remeteu a um outro sinal, o de RISADA. Apontou para a colega Maira, realizou seu sinal e fez o sinal de macarrão. Sorriu novamente da possibilidade de brincar com a língua de sinais, de criar novos sentidos. E assim foi traçando paralelos entre sinais dos amigos e outros sinais que se conectam pela configuração de mão, então sorriu da "rima" que produziu visualmente. A professora bilíngue demorou um tempo para entender o que Talita estava produzindo e, quando entrou no jogo simbólico, sorriu e foi criando paralelos com outros sinais. Talita retomou a brincadeira com o cenário de lego e deixou de produzir rimas com os sinais dos colegas. Neste momento, uma coleguinha ouvinte aproximou-se da professora bilíngue e disse: "quero brincar de casinha com a Talita, você pode dizer isso para ela?". A professora traduziu a fala e auxiliou na configuração dos papéis que cada um teria no ato do brincar. Iniciaram a brincadeira, e uma coleguinha disse: "como não sabemos explicar as coisas para a Talita, ela pode ser nosso cachorrinho? Então podemos brincar de veterinário com 
ela"... A situação angustiou a professora bilíngue, que pensou e disse: “Que falta faz colegas surdos para explorar este momento do brincar, a diferença em contato é importante, mas há uma especificidade da surdez que só se completa na interação e uso de uma língua comum de negociação". Encerrou-se esse primeiro episódio.

Tomamos esta cena para apresentar a importância da língua na relação simbólica do brincar e a necessidade de partilha do código linguístico entre os falantes. Quando Talita afirmou que "esse tipo de brincadeira" os amigos ouvintes não conseguiam brincar, ela remeteu às atividades simbólicas de representação, que requerem um conhecimento de uma língua em comum, no caso, a Libras; e, como mencionado no início deste texto, não tomamos uma língua apenas como um sistema abstrato, pelo conhecimento gramatical dela, mas pela potência de singularização, produção e partilha que ela promove ao falante/sinalizante. Ela percebeu o caráter social e cultural da linguagem, uma vez que a língua tem suas regras constituídas no jogo da linguagem e se origina na prática social. Pequena, com apenas 5 anos, Talita, por ser filha de surdo, sabe que há um significado comum, um sentido produzido entre falantes de uma mesma língua, e que esse sentido vai se produzindo na relação com o outro, à medida que mergulha na corrente da comunicação verbal - oral ou gestual. E essa não relação entre sujeitos que partilham uma mesma língua, ainda que o uso da língua seja singular para cada um, frustrou Talita. Aqui retomamos o conceito discutido anteriormente: se a função do brincar é primordial na Educação Infantil, como conceber salas em que temos apenas uma criança surda? Aprender uma língua, no caso de crianças ouvintes, com o contato de uma aluna surda, não é o mesmo de dominar uma língua para produzir sentidos, brincadeiras, desacordos, acordos, entre outros papéis importantes que são desenvolvidos nessa etapa escolar. Outro ponto a ser retomado é o fato de a aluna perceber em quais momentos do brincar é possível relacionar-se com os colegas ouvintes: no parque. E não em qualquer atividade, mas em algumas, no pula-pula, na gangorra e em outras atividades que envolvam mais o corpo. Ainda assim, há necessidade de mediação da professora bilíngue, que se coloca na fronteira entre ser educadora e intérprete de língua de sinais.

Nessa mesma cena, Talita produziu uma metalinguagem, ou seja, refletiu sobre sua língua, sem saber que estava operando uma descrição linguística. Quando as crianças ouvintes criam rimas na língua oral e produzem frases engraçadas, como: “Mariana cara de banana”, vão construindo, pela sonoridade, uma relação engraçada 
com a língua, que vai ganhando sentidos próprios aos falantes e participantes daquele projeto discursivo. Talita fez isso com as configurações de mãos e foi traçando paralelos dos sinais dos colegas com outros sinais que para ela traziam o riso. Uma das criações propostas por Talita foi a "rima” visual sugerida pela análise de pares mínimos, a configuração de mão (L), construindo um adjetivo para a colega "LAURA SORRIDENTE", que independe da veracidade da afirmação. O fato de apontar o qualitativo "sorridente" para Laura se faz pela relação de igualdade entre as configurações de mão na relação de criação do sinal.

Outra questão a ser destacada diz respeito à necessidade do outro para que a linguagem se desenvolva. Talita sentiu necessidade de um interlocutor, mesmo que adulto, para entrar em sua brincadeira. E os colegas ouvintes tiveram a mesma necessidade, quando propuseram a brincadeira de veterinário, ao perceber a barreira linguística: optaram por dar um papel para Talita no qual a comunicação se limitaria a gestos - "ser o cachorrinho". Nesse sentido, podemo-nos reportar ao conceito de alteridade de Bakhtin (2010) para o estudo da arquitetônica do projeto enunciativo e, com base nessa teoria, anunciamos a importância de pares surdos para potencializar o brincar em suas complexidades simbólicas. Sem limitar ao ser surdo a animalidade na interação, como evidenciado nesta cena. Tais atividades simbólicas, envolvendo o brincar em situação discursiva, eram exploradas pela aluna Talita em anos anteriores com as salas língua de instrução Libras, com mais estudantes surdos.

Talita compreende que é interpretada pelo outro, e o outro que escolhe para brincar com ela (no caso da professora bilíngue) é um outro que a compreende, que a vê como capaz e competente diferentemente da situação dois, exposta anteriormente na brincadeira proposta pelos colegas ouvintes. E, nisso, ela (Talita) também interpreta os outros

6. Apresentamos as imagens dos sinais enunciados por Talita na construção da rima "LAURA SORRIDENTE" por meio de fotos Imagem 1: LAURA;

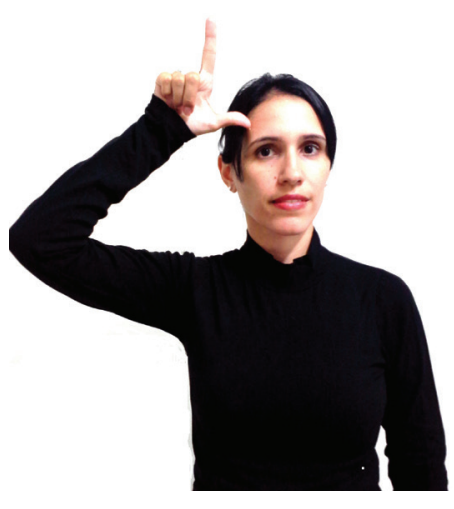

e Imagem 2: SORRISO

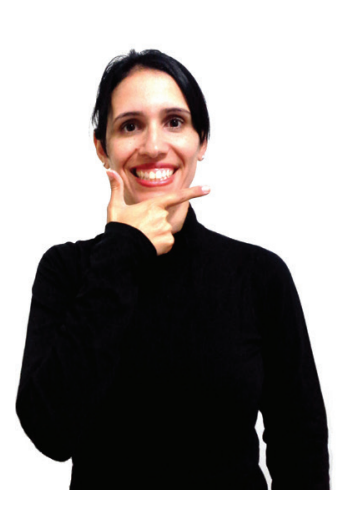


(crianças ouvintes) como interlocutores não adequados para compartilhar com ela do brincar. Dessa forma, além de ser interpretada neste mundo, ela interpreta, faz suas escolhas pautadas nas condições reais de vida, marcadas pela diferença linguística.

Talita domina o brincar, faz uso da flexibilidade discursiva que conduz o real para o imaginário, ao enunciar que Mariana tem cabelo de macarrão e que Luana é um sorriso. "A cada grupo de formas pertencentes ao mesmo gênero, isto é, a cada forma de discurso social, corresponde um grupo de temas" (Bakhtin/Volochinov, 1999, p. 42). Talita revela dominar o gênero narrativo, transitando pelo tema que envolve a brincadeira de forma criativa. Vai manipulando os personagens que constrói e brincando com a língua concomitantemente, faz uso de formas criativas e a refração dos sentidos dos enunciados conduz seu interlocutor para uma contrapalavra. A composição estética de sua enunciação surpreende seu interlocutor, que, inicialmente, não entende a criação, por ser uma construção em outra modalidade, e só percebe esse ato criativo com a linguagem depois de algumas “rimas” produzidas. Notadamente, a professora bilíngue espanta-se com a própria agilidade linguística da aluna e insere-se na brincadeira, pois Talita convoca-a para participar de seu projeto de enunciação. Dessa forma, a partir da perspectiva bakhtiniana de que há uma compreensão responsiva do interlocutor no discurso, isso se evidencia na medida em que Talita propõe um tema e insere a interlocutora, que responsivamente participa e intervém no próprio discurso. A cena narrada apresentou dois grandes eixos de problematizações: a potência de desenvolvimento do pensar, da interação, quando crianças surdas adquirem a língua de sinais o mais cedo possível, como Talita, filha de pais surdos, e, consequentemente, o uso da língua na simbolização por meio do brincar; e a necessidade de interlocutores surdos, uma vez que a falta de domínio da língua por crianças ouvintes, ainda que motivadas para seu aprendizado, limita o espaço de interação e a proposta lúdica, foco na Educação Infantil.

\section{Considerações finais: qual educação infantil bilíngue queremos afirmar?}

A finalização de um texto é sempre a abertura de novos diálogos, pois, no ato da escrita, novas questões se colocam. Algumas considerações podem ser aqui apresentadas como possíveis fechamentos para a problemática anunciada: Educação Infantil bilíngue para surdos e a temática da inclusão. Como apontado, vivemos um momento no qual a escola inclusiva, a escola para todos, é tópico de debate público. Todavia, inúmeros movimentos surdos têm mostrado que a inclusão como ofertada até hoje 
não tem sido eficiente para os alunos surdos. Diante dessa realidade posta, algumas iniciativas têm sido levantadas, como as criações de projetos de escolas Polos bilíngues para adequar a política inclusiva; e a perspectiva bilíngue debatida nos documentos legais que fomentam a educação bilíngue para surdos como direito legal. Tais experiências bilíngues em escolas inclusivas têm gerado novas discussões, que antes não eram previstas: por que há necessidade de ter um grupo de surdos numa mesma sala? É preciso espaço separado dentro da escola regular para surdos nos anos iniciais do Ensino Fundamental e na Educação Infantil? Por que contratar professores surdos, se temos professores ouvintes bilíngues?

Enfim, nosso desafio na escrita deste texto é o de expor a necessidade de consolidação de salas língua de instrução Libras, com a presença de professores bilíngues e surdos desde a Educação Infantil, uma vez que a aquisição da língua de sinais deve se dar o mais cedo possível. Para isso, mostramos uma cena na qual a falta de interlocutores surdos desmotiva o brincar, sendo esta atividade pilar na Educação Infantil. Além disso, mostramos, por meio da apresentação dialógica da aluna surda, que a língua de sinais, quando aprendida desde cedo, exerce as mesmas relações linguísticas de outras línguas para o sujeito: mobiliza o pensamento, promove interações discursivas, coloca o sujeito no universo simbólico. No caso citado, a aluna, filha de pais surdos, tem espaço de aquisição dessa língua em uso real de comunicação. Todavia, isso não ocorre com a maioria de surdos filhos de pais ouvintes.

A proposta é que na Educação Infantil tenhamos esse espaço de constituição da língua de sinais também para os alunos surdos, filhos de pais ouvintes, que vão adquirir a língua na instituição escolar. Portanto, a troca dialógica com sujeitos falantes da Libras só favorecerá esse processo; e, assim, no Ensino Fundamental, se o aluno já fizer uso de uma língua efetiva, o conteúdo a ser trabalhado será mais facilmente assimilado. Destacamos que a atividade de intérpretes nesta etapa de ensino não se mostra eficiente, já que a aprendizagem por processos tradutórios é uma habilidade que requer conhecimento da língua e apresenta-se como uma tarefa mais complexa. Portanto, mais que manter alguns projetos inclusivos bilíngues para surdos em redes isoladas, o que em si já é ótima abertura de diálogo, há que criar uma política linguística que favoreça e garanta a Libras como língua de instrução nas salas de aulas, com profissionais adequados para isso e com a possibilidade de ter mais interlocutores surdos para a troca linguística e a interação direta, sem se dar por processo tradutório na Educação Infantil. 


\section{Referências bibliográficas}

Bakhtin, M. M. (Volochinov, V. N.). (1999 [1929]). Marxismo e filosofia da linguagem (M. Lahud e Yara F. V., trads., 11a ed.). São Paulo: Hucitec.

Bakhtin, M. M. (2010 [1940]). Estética da criação verbal. São Paulo: Martins Fontes.

Góes, M. C. R. de. (2000). A abordagem microgenética na matriz histórico-cultural: uma perspectiva para o estudo da constituição da subjetividade. Cadernos Cedes, XX (50). Recuperado em 10 de agosto de 2015, de http://www.scielo.br/pdf/ ccedes/v2on50/ao2v2050.

Góes, M. C. R. de. (2002). O brincar de crianças surdas: examinando a linguagem no jogo imaginário. Educação On-Line, sem paginação.

Lacerda, C. B. F. de. (1998). A prática fonoaudiológica frente às diferentes concepções de linguagem. Espaço (10), 30-40.

Lacerda, C. B. F. de. (2006, maio/agosto). A inclusão escolar de alunos surdos: o que dizem alunos, professores e intérpretes sobre esta experiência. Cadernos CEDES, 26(69) 163-184,

Lacerda, C. B. F. de. (2009). Intérprete de Libras: em atuação na educação infantil e no ensino fundamental. Porto Alegre: Mediação;FAPESP.

Lacerda, C. B. F. de. (2010). Tradutores e intérpretes de Língua Brasileira de Sinais: formação e atuação nos espaços educacionais inclusivos. Cadernos de Educação $1,133-153$.

Lodi, A. C. B., \& Lacerda, C. B. F. de (Orgs.). (2009). Uma escola, duas línguas: letramento em língua portuguesa e língua de sinais nas etapas iniciais de escolarização. Porto Alegre: Mediação.

Lodi, A. C. B., \& Luciano, R. de T. (2009). Desenvolvimento da linguagem de crianças surdas em língua brasileira de sinais. In A. C. B. Lodi, \& C. B. F. de Lacerda (Orgs.), Uma escola, duas línguas: letramento em língua portuguesa e língua de sinais nas etapas iniciais de escolarização. Porto Alegre: Mediação.

Lodi, A. C. B., Rosa, A. L. M., \& Almeida, E. B. de. (2012). Apropriação da Libras e o constituir-se surdo: a relação professor surdo-aluno surdo em um contexto educacional bilíngue. Revista Virtual de Estudos da Linguagem - ReVEL 10(19).

Martins, V. R. O. (2008). Educação de surdos no paradoxo da inclusão com intérprete de língua de sinais: Relações de poder e (re) criações do sujeito. Dissertação de Mestrado, Faculdade de Educação da Universidade Estadual de CampinasUnicamp, Campinas/SP. 
Martins, V. R. O. (2013). Posição-mestre: desdobramentos foucaultianos sobre a relação de ensino do intérprete de língua de sinais educacional. Tese de Doutorado, Faculdade de Educação, Universidade Estadual de CampinasUnicamp, Campinas/SP.

Martins, V. R. O, \& Lacerda, C B. F. de. (2014). Letramento e surdez: de qual concepção de linguagem estamos falando? In A. A. S Oliveira, R. B. Poker, F. I. W. de Oliveira, \& Y. M. Martínez (Orgs.), Prácticas pedagógicas en educación especial: hacia una escuela inclusiva (pp. 209-226). Universidad de Alcalá.

Martins, V. R. O, \& Souza, R. M. de. (2011). Intérprete de língua de sinais educacional, para além de um instrumento: um rádio (inter) ativo? In E. L. Behares (Org.), LSI: Lengua de Señas e interpretación (2), 69-91.

Morato, E. M. (2000, julho). Vigotski e a perspectiva enunciativa da relação entre linguagem, cognição e mundo social. Educação \& Sociedade, 22(71), 149-165. Retirado em 12 de abril de 2015, de arttext\&pid=S0101-73302000000200007\&lng=pt\&nrm=iso>

Pino, A. (2001). O biológico e o cultural nos processos cognitivos. In E. F. Mortimer, \& Smolka, A. L. B. (Orgs.), Linguagem, cultura e cognição: reflexões para o ensino e a sala de aula (pp. 21-62). Belo Horizonte: Autêntica

Silva, D. N. H. (2002). Como brincam as crianças surdas (2a ed.). São Paulo: Plexus.

Souza, S. J. (1994). Infância e linguagem Bakhtin, Vygotsky e Benjamin. Campinas-SP: Papirus.

Thoma, A. da S. (2006). Educação dos surdos: dos espaços e tempos de reclusão aos espaços e tempos inclusivos. In A. da S Thoma, \& M. C. Lopes, A invenção da surdez II: Espaços e tempos de aprendizagem na educação de surdos. Santa Cruz do Sul: EDUNISC.

Thoma, A. da S., \& Lopes, M. C. (2004). A invenção da surdez: cultura, alteridade, identidade e diferença no campo da educação. Santa Cruz do Sul: EDUNISC.

Thoma, A. da S., \& Lopes, M. C. (2006). A invenção da surdez II: espaço e tempos de aprendizagem na educação de surdos. Santa Cruz do Sul: EDUNISC.

Turetta, B. dos R. (2006). A criança surda e seus interlocutores num programa de escola inclusiva com abordagem bilíngue. Dissertação de Mestrado, Faculdade de Educação, Universidade Metodista de Piracicaba, Piracicaba.

Turetta, B. dos R., \& Góes, M. C. R. de. (2009). Uma proposta inclusiva bilíngue para crianças menores. In A. C. B. Lodi, \& C. B. F. de Lacerda (Orgs.), Uma escola, duas línguas: letramento em língua portuguesa e língua de sinais nas etapas iniciais de escolarização. Porto Alegre: Mediação.

Wajskop, G. (2001). O brincar na pré-escola. São Paulo: Cortez. 


\section{Legislação}

Decreto $n^{0} 5626$ de 22 de dezembro de 2005. Brasília: Presidência da República, Casa

Civil, Subchefia para Assuntos Jurídicos. Retirado em 07/01/2015, de <http:// www.presidencia.gov.br/ccivil/_Ato2004-2006/2005/Decreto/D5626.htm〉.

Lei $n^{0} 10.098$ de 19 de dezembro de 2000. Brasília: Presidência da República, Casa

Civil, Subchefia para Assuntos Jurídicos. Retirado em 07 de janeiro de 2015, de http://www.planalto.gov.br/ccivil_03/leis/110098.htm

Lei no 10.436 de 24 de abril de 2002. Brasília: Presidência da República, Casa Civil, Subchefia para Assuntos Jurídicos. Retirado em (data), de http://www.presidencia. gov.br/CCIVIL/LEIS/2002/L10436.htm.

Lei $n^{0} 12.319$ de $1^{0}$ de setembro de 2010. Brasília. Presidência da República, Casa Civil, Subchefia para Assuntos Jurídicos. Retirado em 07/01/2015, de http://www. planalto.gov.br/ccivil_03/_At02007-2010/2010/Lei/L12319.htm

Submetido à avaliação em 24 de fevereiro de 2015; aprovado para publicação em 18 de agosto de 2015 . 